\title{
CHAPTER 1: Introduction to advancing practice in pain management
}

\author{
Eloise Carr \\ Martin Christensen
}

\section{Introduction}

Textbooks concerned with 'advanced practice' for nursing are frequently preoccupied with discussions of theory. It is a popular subject as a quick internet search on 'advanced practice' or 'advanced nursing' reveals a plethora of books; at least 140 with many focusing on discrete areas of practice e.g. older people, gastroenterology, surgery and oncology. Beyond those with a clinical focus there are books which only consider the legal aspects, research or evaluation. For this book we are solely interested in the 'translation' of advanced knowledge and skills for practice. The gap between theory and practice, in our opinion, has been the exacerbated by the lack of published work telling the stories by those who do this innovative and ground breaking work. In this book we bring these innovators to tell their story of the development, running and evaluation of a service which has advanced our understanding and care of people in pain.

Before moving to these important contributions we need to briefly review our position and understanding of what constitutes 'advanced' or indeed 'advancing practice' as well as cover a brief historical review of growth in the UK and globally. It is also important to offer definitions and differentiate between these roles and others such as the Clinical Nurse Specialist and Nurse Practitioner.

The book explicitly sets the context of advancing practice in pain management and therefore it is important to define pain and give an overview of the prevalence of pain in acute and community settings. This raises a number of issues relating to the challenges or barriers affecting the potential to deliver excellent pain management. Many of these difficulties appear in the chapters but often offer solutions.

\section{Advanced Practice}

In the UK the profound changes in the National Health Service (NHS) coupled with changes in the scope of professional practice is making it possible for nurses to challenge professional boundaries and create and adopt new roles and responsibilities throughout the healthcare sector (Wilson-Barnett et al, 2000; McGee \& Castledine, 2004). Central to these changes has been the continual development of the Advanced Nurse Practitioner (ANP).

The concept of advancing practice is central to the development of nursing practice and has been seen to take on many different forms depending on its use in context. To many it has become synonymous with the work of the advanced or expert practitioner; others have viewed it as a process of continuing professional development and skills acquisition (Wilson-Barnett et al., 
2000; Por, 2008). Moreover, it is becoming closely linked with practice development (Jenkins \& White, 2001; Jackson, 2003). This is where the concept of advancing nursing practice may be ambiguous and confusing, and some of the ambiguity perhaps derives from the inability to effectively define advancing and advanced practice.

It is difficult to discuss advanced practice without reference to the advanced practitioner because the concept and the individual are inextricably linked by the common theme of advanced knowledge and skills. In defining the advanced practitioner and giving an indication of the underlying foundation of advanced practice, the International Council of Nurses (2006, p.12) suggested that the advanced practitioner is:

.... a registered nurse who has acquired the expert knowledge base, complex decision making skills and clinical competencies for expanded practice.

In an earlier mission statement, the United Kingdom Central Council (1996) intimated that advanced practitioners have an eclectic knowledge base, are grounded in practice and support education and research. McGee \& Castledine (2004) have further suggested that advanced nursing practice is a state of professional maturity, one in which practitioners are pioneering innovators and developers of health care. Others give differing accounts of advanced practice and the advanced practitioner but, in essence, the qualities that are inherent within this role revolve around developing professional leadership, higher levels of scholarly enquiry, research, consultation, higher levels of autonomous practice, interprofessional team working and an acknowledgement of the wider political agenda (Dunn, 1997; Fulbrook, 1998; Woods, 1999; Atkins \& Ersser, 2000; Davis \& Hughes, 2002; Royal College of Nursing, 2003; Thompson \& Watson, 2003; Castledine, 2004; Por, 2008).

Where the advanced practitioner role is defined more in line with the personal attributes and abilities of individuals in providing expert care, the essence of advanced practice appears to centre on the continual ongoing acquisition of 'new' knowledge and skills to enhance and complement previous theoretical and practical knowing. This suggests that advanced practice is part of a continuum of advanced and advancing development (Jamieson et al., 2002; Scholes, 2006). However, the problem with the nature of knowledge that defines advanced practice is that it is either heavily focused on a scientific research base or is deeply embedded in practice (Rolfe, 1998); ideally it should encompass and enhance both. Rolfe (1998) constructed a typology of nursing knowledge (Table 1.1) that incorporates scientific, experiential and personal domains, and further characterised these into either theoretical (knowing-that) or practical knowledge (knowing-how). Schon (1983) called this 'knowing-in-action' which is steeped in the practical knowing of the here and now.

These may not reflect the overlapping nature of advanced practice and we suggest that knowinghow knowledge consists of three distinct variables that portray the knowledge inherent in advancing and advanced practice and contain both content and process knowledge (Christensen, 2009). These include knowing-how, which incorporates the practical and experiential knowledge; knowing-why, the theoretical and empirical knowledge; and knowingwhat, which is pattern recognition knowledge reminiscent of Benner's (1984) expert model. If these were reproduced into a framework of knowledge acquisition, knowing-that could actually be the action undertaken by the practitioner based on a full and comprehensive understanding of the situation (Figure 1.1), which can only be achieved through a culmination of knowing-how, what and why. 
knowledge. It is this ability to recognise patterns which is the hallmark of Benner's (1984) expert model in that practitioners form and develop paradigm cases from different patient episodes and approach patient care using previous concrete experiences. As practitioners build up this repertoire of paradigm cases, they reach the expert level. The ability of an expert nurse to identify someone who may be experiencing pain but not showing overt signs, where perhaps a novice nurse would not see this due to lack of previous cases.

The importance of the 'knowing-that' (Ryle, 2000) element of knowledge therefore takes on greater emphasis, particularly within the advanced practice debate, and yet knowing-that is not simply reading a textbook. Therefore, it would appear that the nature of advanced practice lies in the integration of knowing-how-why-what and knowing-that, and the advanced practitioner is the practical exemplar of this transition.

This leads to the question concerning what is needed for an individual practitioner to advance their practice? It would seem reasonable to suggest that, within the context of advancing practice in pain mangement, the most appropriate model may consist of a process in which specialisation, expansion and advancement form the elements necessary to meet the requirements of advanced practice (American Nurses Association, 1995; Hamric et al., 2000). The reasons for this approach are because advancing practice is closely linked with the personal development of the individual (Fulbrook, 1998) and is more focused on the 'how' of practice as opposed to the 'what' of practice (Rolfe, 1998); the what is considered to be more aligned with advanced practice. This highlights the differences between advanced practice and advancing practice as well as basic nursing practice. Therefore, if this model is viewed as a pyramid of development, at its foundation is basic nursing practice and advanced practice at the apex, with progressional elements being specialisation, expansion and advancement (Figure 1.2).

Advancing practice is a continual developmental process which involves refining knowledge and skills to provide the precursor for advanced level practice in a systematic progression of individual professional and personal development. But advancing practice is more than simply acquiring experiential knowledge or academic qualifications at the behest of organisational or professional need. Advancing practice is also a process of continuing professional development utilising research, further education, leadership and clinical practice (Sams, 1996; Wilson-Barnett et al., 2000), all of which culminate in a practitioner who is able to challenge and change professional boundaries, attain professional maturity and achieve higher levels of autonomy.

What is important in terms of advancing practice is the integration of the different types of knowing and the understanding associated with this - the link between thinking and doing. In developing a mixture of knowing-how (practical knowing), knowing-why (theoretical knowing) and knowing-what (pattern recognition) leads to knowing-that. This is the choice of action determined by the practitioner's understanding of the situation. The situation or context of this will be illustrated by advanced (and advancing) practitioners working in the area of pain management.

\section{The context of pain management: definitions and prevalence}

Pain has been defined as a 'whatever the experiencing person says it is and existing whenever he says it does' (McCaffery 1968). This is helpful as it emphasises believing the person and what they say about their pain. In 1979, the International Association for the Study of Pain (IASP) introduced the most widely used definition of pain and defined it as 'an unpleasant sensory and emotional experience associated with actual or potential tissue damage, or described in terms of 
such damage' (Merskey \& Bogduk 1994). Whilst this is useful it does not reflect the definition of chronic pain which McCaffery and Beebe (1989, p. 232) suggest is:

pain that has lasted 6 months or longer, is ongoing on a daily basis, is due to nonthreatening causes, has not responded to currently available treatment methods, and may continue for the remainder of the patient's life.

This is but one definition and whilst the time periods may be different (perhaps 3 months) the essential tenet remains the same for many definitions. Pain can be viewed as a multidimensional experience which reflects emotional, sensory and cognitive elements. The experience of pain is complex and known to be influenced by a multitude of factors including; previous pain experiences, emotion, mood, culture, age, and situation.

The inadequacies of the management of pain have been reported consistently for over thirty years (Marks and Sachar 1973; Fagerhaugh \& Strauss 1977; Svensson et al 2000, Kirou-Mauro et al 2009). Despite improvements in acute pain management though the introduction 'acute pain' teams and new technology such as patient controlled analgesia (PCA) the management of acute pain following surgery has long been reported as problematic in the UK, USA and Europe (Clinical Standards Advisory Group 2000; Dolin et al 2002; Visentin et al 2005). In the community the picture is worse with chronic pain estimated to have a prevalence rate of between $2-40 \%$ (Verhaak et al 1998) and it is particularly problematic for those who are older or have difficulty communicating. In Europe it has been found that chronic pain of moderate to severe intensity occurs in $19 \%$ of adults, seriously affecting the quality of their social and working lives (Brievik et al 2006). For many people which chronic pain they often report poorer self-rated health, mental well-being and social functioning as well as greater levels of depression and work loss (Mallen et al 2005).

The challenges of managing pain have been well documented and it would be fair to say that whilst the management of acute pain and particularly that associated with surgery have shown radical improvement in recent years, many people continue to experience unrelieved chronic or persistent pain which is tremendously debilitating in terms of their function and quality of life. It is interesting that several of the contributors in this book chose to focus the development and delivery of a service for people whose pain was challenging to manage.

\section{Advancing practice in pain management}

The scene and context for this book have been set. Pain management is a challenging arena in which to practice and those committed to making a difference face multiple challenges. So what would constitute advanced nursing practice in pain management? Despite an abundance of papers discussing 'advanced practice' few exist which specifically have discussed the contribution such nurses might make in pain management.

Using the British Nursing Index database and the search term 'Advanced nursing' gives several hundred citations for each year over the past ten years (see Table 1.2) yet adding the word 'pain' generates a fraction of results, on average less than $5 \%$. The paucity of published papers in this area seems at odds with the prevalence pain management and in particular chronic pain. The management of chronic pain has traditionally been a poor relation to acute services and yet 
frequently provides an opportunity for nurses to take a lead in developing care and service delivery.

Despite the scarcity of studies and publications there some excellent examples of advanced nursing in pain management which cover a range of important areas. These range from how the role of the advanced practitioner can lessen the gap between knowledge and practice (SmithIdell et al 2007), to pushing boundaries of prescribing (Berry et al 2007) and developing a telephone service for paediatric patients following spinal surgery (Carznecki et al 2007).

Kohr \& Sawhney (2005) conducted a web-based survey of how Canadian Advanced Nurse Practitioners assisted patients in identifying their patient's pain management needs. One hundred and sixteen nurses responded to the survey and $13 \%$ of these had a speciality practice in pain management. The survey identified known barriers to effective pain management including insufficient education of nurse/physician teams, lack of patient education and lack of clear guidelines. They suggested that ANP had a key role in supporting the use of practice guidelines and working collaboratively with colleagues, patients and their families. Many of the chapters in this book reflect such findings as they describe in detail the tortuous path undertaken to champion a service development. Much of the work has focussed around the development of guidelines, algorithms and documentation to support new services as well as the myriad of other activities which are required to make it happen.

Before concluding this section it is important to bring in a few concluding thought son the attributes of advanced practice in the management of pain. There is no doubt that the highly valued skills relating to technical knowledge, physiology, psychology and sociology are central columns for the structure. There is a collection of other skills, sometimes less emphasised which we believe are integral to the delivery of advanced care and would include the notion of being 'alongside' the patient. The ability to stay with someone as they experience pain, support them and give them a sense of your own sharing of their pain is an immensely skilful activity. The importance being alongside the person in pain is beautifully captured in an inspirational and sensitive book Alongside the patient in pain (Fordham \& Dunn 1994). A recent paper exploring this concept for pain management makes an important connection between nurses' ability to share neurophysical empathy which includes both somatosensory and emotional networks (Cambell-Yeo et al 2008).

\section{Bringing together advanced practice and pain management}

In searching for generic features to pull together the diversity of activities which we believe informs the development of advanced practice in pain management we drew on six important aspects which we wanted our authors to engage with when telling their stories. When describing how the service developed it is easy to lose the essence of this rich and valuable experience so we sought to shape the journey with sub-headings which brought to light processes underlying their achievements. Making transparent this part of the journey permits others to draw on their achievements and 'test' this knowledge in a different setting. It also allows us to critically evaluate these contributions and in particular the 'advanced knowledge' contribution. Asking practitioners to reflect on their 'advanced contribution' recognises the importance of these practitioners having reflective skills (Glaze 2002) but does not necessarily suggest they are developed to full capacity! It was probably the hardest section of each chapter to write.

In chapter 2 Dee Burrows describes how she led a multidisciplinary team in developing a Pain Management Programme and associated services in the independent sector. This chapter 
captures a unique contribution as not only is it about a nurse consultant developing and leading a pain service but the context is outside the normal territory. It is a detailed account of the both the macro and micro considerations as well as an honest account of the struggles and successes; a blueprint for others.

Paul Bibby, in Chapter 3, similarly charts his own course outside the traditional structures of the NHS to describe how he set up a private company to provide a nurse-led clinic for patients with chronic neck [and shoulder] pain within the community. The chapter highlights the importance of policies influencing the provision of pain services and how commissioners, purchasers and those providing services have to work together. The importance of working across boundaries and not being inhibited to explore new boundaries are central to the narrative.

\subsection{Conclusion}

This opening chapter has attempted to put into context the nature of advanced and advancing practice by actively engaging in the ongoing debate about what constitutes advanced and advancing nursing practice within the context of pain management. There is a realisation that the accumulation of academic awards or length of service doesn't necessarily mean the advancement of practice. It is also evident that there exists a dichotomy as to what the true meanings of advanced and advancing practice actually are. Due to the lack of clarity over the two terms we have adopted a working definition of advancing practice to illustrate the work presented here and to focus thinking around what the requirements for advancing practice are. The practitioner who is advancing their practice is able to challenge and change professional boundaries, attain professional maturity and achieve higher levels of autonomy.

The number of people experiencing unrelieved pain and the care available to them highlights the need for care which better meets their needs. The barriers impeding the effective delivery of care relates to the patients, the professionals and the organisations in which pain management takes place. The complexity of these situations requires professionals with vision, leadership, knowledge and skills and a huge amount of tenacity. Each chapter highlights the problem and then provides a rich description of the journey to develop, deliver and evaluate a service. We believe these chapters capture an inspirational collection of practice which highlights advanced and advancing care in pain management. We hope they will provide you with an opportunity to learn, reflect and be inspired. 


\section{References}

Atkins, S., \& Ersser, S.J., 2000. Education for advanced nursing practice: An evolving framework. Journal of International Nursing Studies. 37, 523-533.

Breivik, H, Collett B, Ventafridda V, Cohen R, Gallacher D (2006) Survey of chronic pain in Europe: Prevalence, impact on daily life, and treatment

European Journal of Pain, 10(4):287-333

Cambell-Yeo et al 2008 (Eloise to locate)

Clinical Standards Advisory Group (2000) Services for patients with pain: a summary of the CSAG report on services for NHS patients with acute and chronic pain. http://www.dh.gov.uk/en/Publicationsandstatistics/Publications/PublicationsPolicyAndGuidance/DH _4009217 [accessed 11/11/08]

\begin{tabular}{|c|c|c|c|}
\hline $\begin{array}{l}\text { Dolin SJ, } \\
\text { Effectiveness }\end{array}$ & $\begin{array}{c}\text { Cashman } \\
\text { acute }\end{array}$ & $\begin{array}{l}\text { JN, } \quad \text { Bland } \\
\text { postoperative }\end{array}$ & $\begin{array}{ll}\text { JM } & (2002) \\
\text { pain } & \text { management: }\end{array}$ \\
\hline
\end{tabular}

Castledine, G., 2004. The development of advanced nursing practice in the UK. In: McGee, P., \& Castledine, G., Advanced Nursing Practice (2nd edn), pp.8-16. Oxford, Blackwell.

Christensen, M. Advancing Practice in Critical Care: A Model of Knowledge Integration. 2008. Nursing in Critical Care. 14(2), 86-94

Davis, B., \& Hughes, A.M., 2002. Clarification of advanced nursing practice: Characteristics and competencies. Clinical Nurse Specialist. 16, 147-152.

Dunn, L., 1997. A literature review of advanced clinical nursing practice in the United States of America. Journal of Advanced Nursing. 25, 814-819.

Fagerhaugh S.H. \& Strauss A.(1977) Politics of Pain Management. Addison-Wesley, Reading, Massachusetts.

Fordham M. \& Dunn V. (1994) Alongside the Patient in Pain: Holistic. Care and Nursing Practice. Balliere Tindall, London.

Fulbrook, P., 1998. Advanced practice: the 'advanced practitioner' perspective. In: Rolfe, G., \& Fulbrook, P., Advanced Nursing Practice, pp.83-102. Oxford, Butterworth-Heinemann.

International Council of Nurses, 2006. Definition and Characteristics of the Role. Geneva, ICN.

International Associated for the Study of Pain 1986 Classification of chronic pain. Descriptions of chronic pain syndromes and definitions of pain terms. Pain, Supplement 3, S1-S226.

Jamieson, L., Mosel-Williams, L., Dwyer, T., 2002. The need for an advanced nursing practice role for Australian adult critical care settings. Australian Critical Care. 15(4), 139-145.

Kirou-Mauro AM, Hird A, Wong J, Sinclair E, Barnes EA, Tsao M, Cyril Danjoux C Chow E 
(2009) Has Pain Management in Cancer Patients with Bone Metastases Improved? A SevenYear Review at An Outpatient Palliative Radiotherapy Clinic Journal of Pain and Symptom Management, 37(1): 77-84

Manzoukas S \& Watkinson S (2006) Review of advanced nursing practice: the international literature and developing the generic features. Journal of Clinical Nursing; 16:28-37

Mallen C, Peat G, Thomas E \& Croft P (2005) Severely disabling chronic pain in young adults: prevalence from a population-based postal survey in North Staffordshire. BMC Musculoskeletal Disorders, 6:42

Marks, R. and E. Sachar (1973). Undertreatment of Medical In-Patients with Narcotic Analgesics. Annals of Internal Medicine 78(2): 173-181.

McCaffery M., 1968 Nursing practice theories related to cognition, bodily pain and nonenvironment interactions, University of California, Los Angeles, California

McCaffery M, Beebe A. (1989) Pain: clinical manual for nursing practice. St. Louis: CV Mosby Co.

Merskey and Bogduk, (1994) Classification of chronic pain, IASP Press, Seattle, WA

Schober M, Affara F. Advanced Nursing Practice. London: Blackwell Publishing; 2006.

Verhaak PM, Kerssens JJ, Dekker J, Sorbi MJ, Bensing JM (1998) Prevalence of chronic benign pain disorder among adults: a review of the literature, 77:231-239

Por, J., 2008. A critical engagement with the concept of advancing nursing practice. Journal of Nursing Management. 16, 84-90.

Rolfe, G., 1998. Education for the advanced practitioner. In: Rolfe, G., \& Fulbrook, P., Advanced Nursing Practice, pp.271-280. Oxford, Butterworth-Heinemann.

Royal College of Nursing, 2003. Nurse Practitioners: An RCN Guide to the Nurse Practitioner Role, Competencies and Programme Accreditation. London, RCN.

Scholes, J., 2006. Developing Expertise in Critical Care Nursing. Oxford, Blackwell Publishing.

Schon, D.A., 1983. The Reflective Practitioner: How Professionals Think in Action. London, Ashgate.

Thompson, D.R., \& Watson, R., 2003. Advanced nursing practice: What is it? International Journal of Nursing Practice. 9, 129-130.

Visentin M, Zanolin E, Trentin L, Sartori S, de Marco R. (2005) Prevalence and treatment of pain in adults admitted to Italian hospitals. European Journal of Pain. 2; 9(1):61-7

Wilson-Barnett, J., Barriball, L.K., Reynolds, H., Jowett, S., \& Ryrie, I., 2000. Recognising advancing nursing practice: Evidence from two observational studies. International Journal of Nursing Studies. 37, 389-400. 
Woods, L.P., 1999. The contingent nature of advanced nursing practice. Journal of Advanced Nursing. 30(1), 121-128. 